\title{
A Pesquisa de Territorialidades Ambientais em Estudos Pós-Coloniais do Jornalismo na Amazônia
}

\author{
Research into environmental territorialities of postcolonial studies of journalism on the
} Amazon

\begin{abstract}
Simão Farias de Almeida - Universidade Federal de Roraima | Boa Vista | Roraima | Brasil | E-mail: simon-jp@hotmail.com | https://orcid.org/0000-0001-8582-7485
\end{abstract}

Resumo: O conceito de territorialidade incide numa problemática metodológica e teórica antes mesmo de migrar aos campos da comunicação e do jornalismo. Os estudos pós-coloniais podem contribuir na percepção de conflitos identitários nele envolvidos, capazes de elucidar e legitimar os sentidos das lutas políticas, econômicas, sociais, culturais e ambientais comuns às territorialidades humanas e não humanas. Partiremos das discussões em torno do termo na geografia e no contexto amazônico, para, em seguida, ilustrar as representações de territorialidades ambientais na comunicação indígena, como forma de pesquisar os fatores e os contextos complexos, multivalentes e sobrepostos na cobertura jornalística de demandas de sujeitos minoritários por ocupação territorial na Amazônia brasileira. Pretendemos sugerir pautas e objetos de estudo a respeito das singularidades da temática na região, tendo em vista a coexistência da sua diversidade social, étnica e de ecossistemas naturais.

Palavras-chave: Territorialidade ambiental. Estudos pós-coloniais. Comunicação das minorias. Comunicação indígena. Jornalismo na Amazônia.

Abstract: The concept of territoriality is reflected in a methodological and theoretical problem even before migrating to the fields of communication and journalism. Postcolonial studies may contribute to the perception of identity conflicts involved within it and are capable of clarifying and legitimizing the meanings of the political, economic, social, cultural and environmental struggles common to human and non-human territorialities. Our starting point is taken from discussions surrounding the term in geography and the Amazonian context, leading on to illustrate the representations of environmental territorialities in indigenous communication, as a manner in which to research the complex, multivalent, overlapping factors and contexts in the journalistic coverage of the demands by minorities for territorial occupation in the Brazilian Amazon. Our intention is to suggest guidelines and objects of study regarding the singularities of the theme in the region, in view of the coexistence of their social and ethnic diversity and natural ecosystems.

Keywords: Environmental territorialities. Postcolonial studies. Communication of minorities. Indigenous communication. Journalism on the Amazon.

- Recebido em: 11 jun. 2019 • Aprovado em: 07 ago. 2019 - e-ISSN: 2177-5788

DOI: https://doi.org/10.22484/2177-5788.2019v45n2p387-408

Copyright @ 2019. Conteúdo de acesso aberto, distribuído sob os termos da Licença Internacional da CreativeCommons - CC BY-NC-SA - Atribuição Não Comercial (https://br.creativecommons.org/licencas/) - Permite distribuição e reprodução, desde que atribuam os devido créditos à publicação, ao autor(es) e que licenciem as novas criações sob termos idênticos. 


\section{Introdução: territorialidades na Amazônia}

O objetivo das discussões teóricas e críticas neste artigo é demonstrar as contribuições dos estudos pós-coloniais e de seus sentidos de agência na percepção da preeminência da cultura política dos sujeitos, engendrada nas questões de territorialidades humanas e ambientais, das suas lógicas e lutas políticas, econômicas, sociais e culturais. Os debates a respeito não devem fugir da problemática conceitual, metodológica e teórica de termos e paradigmas. A criação do Programa de Pós-Graduação em Comunicação da Universidade Federal de Roraima (UFRR), na área de concentração Comunicação, Territorialidades e Saberes Amazônicos, estimula-nos a propor as discussões aqui presentes a partir das quais direcionaremos nossas atividades de docência e pesquisa no curso de mestrado vinculado ao programa. Devemos vislumbrar essa problemática nas ciências naturais e humanas, na comunicação e no jornalismo, nos contextos amazônicos e indígenas.

Proveniente do campo do conhecimento geográfico, o termo territorialidade não pode ser confundido com os sentidos de lugar, espaço e território. O teórico da geografia humana, Saquet (2010), evita a problematização ao defender que as relações entre os sujeitos constituem histórica e geograficamente territórios e territorialidades, sem distinguir os aspectos contextuais e identitários de cada um dos dois conceitos. Segundo Saquet (2010), as identidades perpassam por uma lógica de desterritorialização e reterritorialização. No entanto, tais processos, pelo menos à primeira vista, não dão conta das políticas de pertencimento por parte das minorias sociais e étnicas diante dos conflitos e das crises econômicas e sociais generalizadas.

Apesar de enumerar as diferentes perspectivas que compõem as lutas dos sujeitos, persiste na confusão conceitual: 
As forças econômicas, políticas e culturais que condicionam o território e a territorialidade, geram a desterritorialidade e as novas territorialidades, num único movimento, complexo e heterogêneo. Por isso, é necessário contextualizar esses processos em cada momento, período e lugar, num constante e concomitante movimento de desterritorialização e reterritorialização (SAQUET, 2010, p. 164, grifo do autor).

A complexidade e heterogeneidade de forças estão relacionadas aos processos e não às demandas identitárias de fatores econômicos, políticos e culturais. Deste modo, o mesmo autor hierarquiza os aspectos e as mudanças do espaço geográfico em detrimento das interferências espaciais do componente humano, mesmo também considerando suas mobilidades e mudanças e seu pressuposto metodológico de identificação e explicação dos distintos níveis territoriais ou escalas de atuação implica na abordagem multiescalar e multitemporal de des-continuidades dos indivíduos. Trata-se de um método de pesquisa sobre os processos territoriais dos sujeitos, mais do que a respeito dos sujeitos nas suas territorialidades. O fato de o teórico reconhecer o estudo da natureza desvinculado dos aspectos do homem nos espaços naturais reforça esse recorte: "A natureza está presente na construção histórica do território e da identidade, como patrimônio de cada lugar e que, por isso, precisa ser gerida com vistas ao desenvolvimento territorial sustentável" (SAQUET, 2010, p. 148, grifo do autor).

Costa (2012, p. 365), ao contrário de Saquet (2010), se esforça na problematização dos conceitos, sem confundi-los:

Nem "fim da espacialidade", inerente à existência do mundo, nem "fim da territorialidade", inerente à condição humana, a desterritorialização é simplesmente a outra face, sempre ambivalente, da construção de territórios. Mas não se trata apenas de uma ambivalência no sentido das contradições da "modernidade". Não se trata simplesmente da articulação contraditória entre verso e reverso. Des-territorialização (sempre hifenizada), tal como a multiterritorialização do nosso tempo, carrega sempre a própria multivalência, o múltiplo, o sincrético ou, se quisermos, para usar o termo da moda, uma "condição híbrida". 
O autor brasileiro sugere que a ideia de fim da territorialidade, pregada pelos teóricos da pós-modernidade, implica na morte dos sujeitos, daí apontar a ambivalência e multivalência dos distintos processos de (des)ocupação territorial e de seus atores sociais. Além disso, parte do "complexo amálgama sociedade-natureza" para compreender como as questões ambientais afetam a organização territorial. De acordo com ele, as tragédias ambientais "são suficientes para que, no mínimo, nos questionemos sobre alguma forma de incluir a dinâmica da natureza no nosso debate sobre os processos de des-territorialização" (COSTA, 2012, p. 368-369).

Assim, marca a multivalência dos contextos naturais e humanos, além de suas interferências mútuas, delimitando assim os sentidos do conceito de territorialidade. Costa (2012, p. 372) ainda destaca as múltiplas velocidades, os diversos ritmos e níveis de des-re-territorialização,

[...] especialmente aquela entre a minoria que tem pleno acesso e usufrui dos territórios-rede capitalistas globais que asseguram sua multiterritorialidade, e a massa ou os "aglomerados" crescentes de pessoas que vivem na mais precária territorialização ou, em outras palavras, mais incisivas, na mais violenta exclusão e/ou reclusão socioespacial.

Ele delimita as distintas demandas das elites políticas, econômicas e sociais, e das minorias vítimas das ocupações precárias. Oferece o ponto de partida teórico para pensarmos pressupostos pós-coloniais na pesquisa de territorialidades ambientais no jornalismo da Amazônia. Não poderemos fugir das discussões das territorialidades indígenas, caras aos processos de democratização dos espaços geográficos na região Norte do Brasil. Nosso propósito neste artigo é compreender as complexidades humanas e não humanas envolvidas. O indígena é um dos principais atores em favor da luta pelo meio ambiente preservado.

Sousa e Almeida (2015, p. 77-80) demonstram que as territorialidades implicam em conflitos de legitimidade de identidades territoriais: 
As territorialidades indígenas seguem princípios bem diversos, muito relacionados à organização social, às representações culturais, aos conhecimentos e às tecnologias de exploração dos recursos naturais $[\ldots]$

[...] em decorrência dos processos de ocupação e colonização de seus territórios, os povos indígenas passam a se inserir na sociedade e nos Estados nacionais, fazendo com que suas territorialidades sofram um processo de ajuste ou incorporação pelas lógicas territoriais do Estado. Esta incorporação, por sua vez, é antes fruto de um processo de imposição do Estado do que uma adesão dos povos indígenas às novas lógicas territoriais.

A luta dos povos indígenas pelo reconhecimento de suas terras inclui fatores políticos, econômicos, sociais, culturais e ambientais. Isso se deve porque o usufruto do território não é automático e nem natural, mas confronta as lógicas do Estado de controle dos espaços humanos e naturais.

Por outro lado, a territorialidade indígena não pode ser vista como algo fixo e nem garantido de forma definitiva, tendo em vista que a legitimidade das identidades é um processo contínuo. $\mathrm{O}$ fato de indivíduos e agrupamentos nativos manterem contato com espaços e aglomerações urbanas não significa adaptação ou perda de sua condição natural de sujeitos. "É importante ressaltar que, entre alguns povos, há alterações visíveis no seu modo de vida, sem contudo significar a perda de identidade e de sua lógica própria de pensar o mundo" (SOUSA; ALMEIDA, 2015, p. 135). As territorialidades e as perspectivas identitárias compartilham, portanto, do aspecto comum de ser uma construção permanente. Apesar de não ser pacífica, possui propósitos delimitados para alcançar resultados benéficos às individualidades e coletividades. Seus processos de desterritorialização e reterritorialização, consequentes das relações com outros povos, não significam anulação de suas identidades:

O contexto relacional diverge, portanto, de povo para povo, de região para região, e é muito dinâmico, da mesma forma como são as relações sociais, sempre em permanente transformação. Agentes externos, com os quais um povo indígena mantém vínculos mais estreitos durante determinado tempo, podem, num outro momento, não mais fazer parte do conjunto de relações (SOUSA; ALMEIDA, 2015, p. 218). 
Assim, as mudanças das lógicas territoriais não estão diretamente condicionadas às alterações identitárias, além disso, elas variam de um povo indígena a outro. Algumas terras são extensas e têm abundância de recursos naturais, porém há aquelas menores, muito degradadas e pressionadas pelo seu entorno (SOUSA; ALMEIDA, 2015, p. 221). A pesquisa a respeito de territorialidades humanas e ambientais, deste modo, deve considerar as particularidades e diferenças de região a região. É possível perceber crises generalizadas em algumas terras indígenas, onde o uso intensivo de recursos naturais pode comprometer a perda de biodiversidade e os processos ecológicos necessários à recomposição e à sustentabilidade desses recursos, causando impactos negativos nas economias indígenas (SOUSA; ALMEIDA, 2015, p. 157).

Sousa e Almeida (2015), são assertivos ao utilizar os termos sinergia espacial e condicionantes territoriais referentes a essas territorialidades. Suas culturas dependem da integridade do meio ambiente fundamental a seu bem viver, e a própria natureza é beneficiada pelo cuidado oferecido por parte dos povos indígenas. Todavia, a demarcação de terras nem sempre garante essa harmonia entre as territorialidades humanas e ecológicas. A sinergia homem e ecossistema natural depende de "apoio para a readequação às novas realidades das terras demarcadas, que é o que se espera de uma política de gestão territorial indígena" (SOUSA; ALMEIDA, 2015, p. 156-157). Por um lado, as condicionantes territoriais, muitas vezes, limitam os recursos naturais disponíveis às comunidades. Por outro lado, os saberes tradicionais precisam se adaptar a "novas atividades e tecnologias econômicas que demandam compreensão por parte dos representantes indígenas tanto da legislação quanto das consequências dos impactos ambientais, sociais e econômicos delas provenientes" (SOUSA; ALMEIDA, 2015, p. 259).

Portanto, os contextos e processos territoriais são permeados de complexidade devido à multivalência de fatores diversos atrelados a condições engendradas em uma policrise, nos termos de Morin (2003), para 
quem devemos buscar a relação de inseparabilidade e de interretroação entre todo fenômeno e seu contexto, na qual transitam problemas da política, da economia, da demografia e da ecologia.

A pesquisa de territorialidades ambientais na Amazônia cobra do pesquisador o conhecimento das particularidades multivalentes da região. Becker (1991, p. 87) compreende a complexidade da policrise amazônica caracterizada pela presença de diversidade humana num espaço de variedade da biodiversidade natural:

[...] a substituição da mata pela pastagem tem predominado no processo de desmatamento. Para os pequenos agricultores, ela é a alternativa imediata para a valorização da terra degradada logo após as primeiras culturas anuais, incapazes de reciclar os nutrientes para o solo. Para os latifundiários, a pecuária é a extensão do desmatamento como instrumento de legitimação jurídica da propriedade. E a substituição da mata por capim significa maior proporção de fósforo no solo e maior erosão porque o escoamento de água no pasto é dez vezes maior do que na floresta.

A crise política, econômica, social e ambiental generalizada impacta a floresta por meio das interferências da agricultura e da pecuária. A problemática da crônica sinergia territorial na Amazônia se caracteriza pela proximidade ou superposição de territórios indígenas a outros favoráveis à mineração, constituindo um dos mais concretos impasses do processo de ocupação (BECKER, 1991, p. 78). A fragmentação dos ecossistemas avançou com as intervenções estatais e autônomas de diversos grupos humanos:

A integração homogeneizadora imposta pela malha programada do governo federal não é de forma alguma absoluta nem total. A Amazônia nunca foi homogênea, e hoje, submetida a um rápido processo de destruição/construção, também se fragmenta em unidades sub-regionais constituídas por novas sociedades locais. Essa diferenciação é resultado da ação do Estado e da iniciativa e do confronto dos diferentes grupos sociais, isto é, da prática social (BECKER, 1991, p. 96).

Essas interferências apenas tornaram mais complexa a compreensão das distintas territorialidades demarcadas pelos variados povos indígenas em busca de legitimidade de suas identidades culturais. A modernidade tardia enquanto processo industrial-agrário e político-econômico 
problematizou os já complexos contextos e fatores. A questão ecológica se envolve numa trama engrenada nos paradoxos do modelo brasileiro nacional/transnacional e da política de ocupação regional:

A polêmica sobre a Amazônia brasileira é alçada a uma escala planetária, sob a qual jazem interesses ecológicos, tecnológicos e políticos. A tecnologia avançada cria condições para a exploração da floresta e dos rios, sucedendo-se rapidamente novas frentes contraditórias. A tecnologia energética submerge a floresta ou a transforma em biomassa para produção de energia; a da engenharia genética preserva a floresta como "paraísos experimentais" para o vetor científico-tecnológico moderno. O descompasso tecnológico dessas frentes, somado aos problemas de degradação ambiental já existentes, gera interesses conflituosos entre atores internacionais e nacionais, com as mais esdrúxulas alianças" (BECKER, 1991, p. 83).

A modernidade tardia precarizou a degradação ecológica na Amazônia, no entanto, não podemos dizer que as tentativas dos povos indígenas e tradicionais de reforçar suas necessidades territoriais e identitárias fracassaram. Freitas (2003) concorda com a noção de desenvolvimento sustentável e preservação da biodiversidade aliada às configurações sociais de diversidade cultural na região, confrontando novas formas de dominação e colonialismo por parte de lideranças científicas, políticas e empresariais. Neste sentido, as comunidades amazônicas não devem ser preteridas de um projeto de preservação ambiental da floresta, mediante a desculpa essencialista de meio ambiente livre da presença humana. Elas podem contribuir na conservação ecológica e garantir sua sobrevivência por meio dos recursos naturais sem destruí-los. Seus processos de territorialidade implicam nas formas dos sujeitos de atribuir ao território o jogo ambivalente de poder e de necessidade política, econômica, social e ambiental dos distintos atores. Nestes termos, a discussão pós-colonial de territorialidades ambientais na Amazônia encontra nos sentidos do conceito lugares privilegiados para discutir a posição dos sujeitos e de suas identidades frente às lógicas de dominação na ocupação, à sobreposição, à sinergia e aos condicionantes de distintos territórios. 
A compreensão da comunicação e do jornalismo neste cenário precisa passar pelo contraponto à visão totalitária e homogênea de território, na verdade fragmentado pelas demandas de representação política e cultural das minorias. Não nos preocuparemos com a distinção entre a mediação de públicos e líderes de opinião, e a midiatização dos meios ao tratarmos das teorias da comunicação aqui referenciadas. Interessa-nos a aplicabilidade de seus pressupostos no jornalismo, considerado um dos campos da comunicação de massa.

\section{A Comunicação das Minorias e a Natureza}

O debate sobre as representações da territorialidade na comunicação social e no jornalismo ainda é incipiente. Jesús Martin-Barbero é um dos poucos teóricos latino-americanos que sinaliza a discussão a respeito da espacialidade da cidade e do território no campo comunicacional. Ele associa os conceitos de territorialização e identidade no contexto da modernidade tardia:

Tocamos assim o solo da cena "tardomoderna" e do movimento que desterritorializa as identidades e volta a fundar o sentido das temporalidades. A inscrição da comunicação na cultura deixou de ser simples assunto cultural, pois são tanto a economia como a política as envolvidas aqui diretamente no que se produz. É aquilo que, ambígua mas certeiramente, dizem expressões como "sociedade da informação" ou "cultura política"; e de um modo ainda mais obscuro, mas também certo, é o que conta a experiência cotidiana das desarraigadas populações de nossas cidades (MARTIN-BARBERO, 2004, p. 227-228).

Apesar de situar a complexidade de fatores políticos, culturais e sociais atrelados ao pensamento da comunicação a partir da cultura, nos contextos sobrepostos da urbanidade tardomoderna e do cotidiano das cidades, Martin-Barbero não reconhece as lutas das minorias com intuito de consolidar suas identidades através da garantia de legitimidade dos seus processos de territorialidade. A modernidade agrário-industrial tardia no subcontinente americano, segundo ele, desterritorializa as identidades, como se elas fossem fluidas demais para não ter apelo político e cultural de reafirmação dos lugares de vida e de fala. Deste modo, suas discussões 
teóricas servirão apenas enquanto ponto de partida rumo a pressupostos capazes de oferecer sentidos de reconhecimento da luta de sujeitos por dignidade individual e coletiva diante das lógicas territoriais do Estado e do mercado financeiro.

A filósofa pós-colonial Gayatri Spivak fala em agência etnocultural que permite o sujeito subalterno falar de dentro dos espaços de poder e garantir cidadania: "Então uma linha de comunicação é estabelecida entre um membro de grupos subalternos e os circuitos de cidadania ou institucionalidade, o subalterno tem sido inserido num longo caminho hegemônico"1 (SPIVAK, 1999, p. 310, tradução nossa). Ao agenciar esses espaços, segundo Spivak (1999), as minorias podem falar por elas mesmas. Elas também se expressam em favor de outros seres desprovidos de linguagem verbal. Outros sentidos de agência pós-colonial contribuem para esta compreensão.

Mark Orbe nos ajuda no início desse percurso metodológico ao defender a teoria da comunicação co-cultural. Esse tipo de comunicação envolve as estratégias dos grupos minoritários de ter voz nos espaços de poder:

\begin{abstract}
Especificamente, a teoria co-cultural trabalha para criar uma estrutura que promove um maior entendimento de processos intrínsecos pelos quais membros de grupos co-culturais (mulheres, pessoas de cor, gays, lésbicas, bissexuais, etc) negociam tentativas por meio de outros a render suas vozes modificadas dentro das estruturas sociais dominantes. É inerente a esta análise de comunicação co-cultural a atenção às semelhanças e diferenças dentro e entre grupos co-culturais ${ }^{2}$ (ORBE, 1998, p. 4, tradução nossa).
\end{abstract}

1 Then a line of communication is established between a member of subaltern groups and the circuits of citizenship or institutionality, the subaltern has been inserted into the long road to hegemony" (SPIVAK, 1999, p. 310).

2 Specifically, co-cultural theory works to create a framework that promotes a greater understanding of the intricate processes by which co-cultural group members (women, people of color, gays, lesbians, bisexuals, etc) negotiate attempts by others to render their voices muted within dominant societal structures. Inherent in its analysis of cocultural communication in attention to the commonalities and differences between and among co-cultural groups (ORBE, 1998, p. 4). 
As minorias sociais compartilham de formas de comunicação comuns entre si, e cada grupo possui suas particularidades. Orbe (1998) enumera cinco premissas da teoria co-cultural: a hierarquia social em cada país privilegia certos grupos majoritários em detrimento de outros; membros desses grupos dominantes usam o sistema comunicacional a fim de refletir, reforçar e promover suas experiências; a comunicação dominante impede o progresso social de pessoas de outros grupos fora de suas estruturas; membros dos grupos co-culturais com matriz diversificada de experiências vividas compartilham posição social similar da estrutura dominante; contra a opressão dos grupos majoritários, as minorias adotam comportamentos comunicacionais de confronto aos limites da comunicação pública. Orbe (1998) também aponta seis fatores intrínsecos às práticas dos grupos minoritários: preferências particulares, campo de experiências, habilidades, contexto situacional, percepção de custos e recompensas, abordagem da comunicação. Ainda segundo Orbe (1998), o confronto com as estruturas sociais dominantes inclui estratégias de assimilação assertiva, não assertiva e agressiva, acomodação assertiva e agressiva, separação não assertiva, assertiva e agressiva e elas podem ser pró-ativas ou reativas, dependendo como os membros dos grupos minoritários lidam com membros majoritários de grupos sociais dominantes. Iremos enumerar as estratégias mais comuns por parte da comunicação co-cultural entre dominados e majoritários.

Uma das práticas reativas é a dissipação de estereótipos, e sua manipulação é um comportamento comunicativo assertivo de assimilação das causas das minorias:

A comunicação co-cultural pratica o ato de evitar e a dissipação de estereótipos que membros de grupo dominante atribuem a diferentes grupos co-culturais. Mesmo assim, manipulando estereótipos, como a comunicação co-cultural pratica, não tenta desafiar os estereótipos existentes, mas explorá-los para ganho pessoal. Em outras palavras, em vez de evitar ativamente ou inadvertidamente dissipar comportamentos estereotípicos, alguns 
membros de grupos co-culturais obtém benefícios em comum acordo com outros grupos ${ }^{3}$ (ORBE, 1998, p. 65, tradução nossa).

Dissipar estereótipos implica em recusar determinadas características impostas pelos grupos dominantes às minorias. Manipulá-los corresponde a explorar alguns deles com a finalidade de ganho pessoal e coletivo, caso de atribuição de força física aos negros. Através da adoção assertiva de estereótipos, "[...] realizam uma leitura negociada de estereótipos culturais pelos quais eles adotam a ideologia dominante em linhas gerais, mas seletivas, aplicados em casos específicos e rejeitados em outros"4 (ORBE, 1998, p. 66, tradução nossa), ou seja, utilizam alguns deles positivamente a seu favor. Orbe, nesse caso, exemplifica o caso de homens gays que estão mais abertos à adoção de estilo na escolha de roupas, design e cores.

A comunicação assertiva da cultura não familiar de um grupo minoritário desconhecida pelos majoritários, capaz de arregimentar apoiadores de sua causa e de experiências comuns, constitui a estratégia de comunicar o eu.

Este processo de "fazer o não usual ser visto usual" (Woods, 1993, p. 184) é o último resultado da comunicação continuada do eu; no entanto, é algo normalmente não alcançado através de uma tentativa consciente de quebrar crenças estereotipadas. Em vez disso, é um subproduto da presença desses membros de grupo cocultural que se esforçam para ser vistos como complexos, indivíduos multidimensionais, não simplesmente um membro de grupo cocultural $^{5}$ (ORBE, 1998, p. 73, tradução nossa).

3 The co-cultural communicative practices of avoiding and dispeling stereotypes that dominat group members assign to different co-cultural groups. Nevertheless, manipulating stereotypes, as a co-cultural comunicative practice, does not attempt to challenge existing stereotypes but to exploit them for personal gain. In other words, instead of actively avoiding or inadvertently dispelling "stereotypical" behaviors, some members of co-cultural groups conform to commonly accepted ones to obtain certain benefits (ORBE, 1998, p. 4).

4 "[...] undertake a negotiated reading of cultural stereotypes by which they adopt the dominant ideology in broad outline but selective apply it in specific cases and reject it in others" (ORBE, 1998, p. 66).

5 This process of "making the unusual seem usual" (Woods, 1993, p.184) is the ultimate result of continued communicating self; however, it is one that is not typically achieved through a conscious attempt to break stereotypical beliefs. Instead, it is a by-product of the presence of those co-cultural group members who strive to be viewed as complex, 
A expressão da individualidade conta com o esforço do membro para ser visto como indivíduo complexo e de variadas dimensões. O estranhamento em relação ao sujeito minoritário se dissipa, tendo em vista a demonstração de características comuns entre grupos dominantes e dominados. A acomodação assertiva dos grupos co-culturais, conforme Orbe (1998), também inclui a estratégia de educar os majoritários de modo que as minorias consigam transpor a opressão em espaços nos quais têm acesso, aceitação e sucesso. As interações dentro do grupo minoritário constituem um trabalho interno e facilitam o encorajamento de seus membros contra as práticas opressivas. "Esses indivíduos são mais hábeis a identificar, e posteriormente entender, questões relacionadas ao funcionamento em definições que não são representativas - nem necessariamente solidárias - de sua posição co-cultural"6 (ORBE, 1998, p. 74, tradução nossa). A educação interna facilita a identificação de manobras dominantes dentro dos grupos.

A tática não assertiva de ampliar a visibilidade, segundo Orbe (1998), implica numa estratégia de presença de indivíduos de minorias sociais nos espaços tradicionais e oficiais de poder; já a tática de confronto agressivo é usada por alguns membros através de linguagem coercitiva, questionamento de práticas políticas e dominantes, uso de agressividade não verbalizada e de ultimato aos majoritários. Ainda segundo Orbe (1998), comportamentos agressivos verbalizados constituem a estratégia de ataque por meio de linguagem ofensiva, confronto contra características do opressor e sarcasmo, sendo que ela tem a finalidade de afastar os membros majoritários, enquanto a sabotagem do outro pretende prejudicar a eficácia da opressão e unir forças contra ela.

multidimensional individuals, not simply a member of one co-cultural group (ORBE, 1998, p. 73).

6 "These individuals are better able to identify with, and subsequently understand, the issues related to functioning in settings that are not representative - nor necessarily supportive - of your co-cultural positioning" (ORBE, 1998, p. 74). 
Deste modo, o uso de estratégias não assertivas, assertivas e agressivas por parte dos grupos co-culturais tem o papel de contrapor os meios dominantes a fim de garantir a liberdade cultural, a força e a comunicação dos membros minoritários nos espaços de poder. A comunicação ambiental das minorias pode fazer com que elas usufruam de uma sociedade e do meio ambiente livres de práticas opressivas e destrutivas.

A filósofa pós-colonial Plumwood (2002, p. 5) aponta o construto ideológico do racionalismo de "contaminar" a natureza de emoções, atributos e expressões compatíveis aos propósitos antropocêntricos. Para a mesma autora, a prudência deve passar pela recusa de atribuir posse humana aos espaços naturais. Eles devem ser vistos não por meio do dualismo racionalista homem/natureza, mas através de um agenciamento ético que fala e trabalha pelos seres animados e inanimados sem voz e pensamento. "Concepções hegemônicas e racionalistas de agência humana tratam igualmente as minorias e a natureza numa relação de dependência" (PLUMWOOD, 2002, p. 34). Ao contrário disso, ela legitima uma comunicação intercultural ética entre seres humanos, não humanos e o meio ambiente.

Um argumento relacionado seria que, embora os não humanos tenham intencionalidade, subjetividade e comunicação, a representação dessa comunicação nos termos da fala humana é sempre invalidamente antropomórfica, retratada em termos excessivamente humanos. No entanto, isso parece exigir perfeição e ser excessivamente geral, e poderíamos apelar ao fenômeno paralelo da tradução transcultural para argumentar que nem todos os esforços de tradução estão condenados. A falta de comunicação e assimilação não é o resultado inevitável, embora existam, como no caso humano, melhores e piores tentativas de tradução (PLUMWOOD, 2002, p. 60, tradução nossa) ${ }^{7}$.

7 A related argument would be that, although non-humans do have intentionality, subjectivity and communication, the representation of that communication in the terms of human speech is always invalidly anthropomorphic, depicted in excessively human terms. This however seems to demand perfection and to be over-general, and we could appeal to the parallel phenomenon of cross-cultural translation to argue that not all translation efforts are doomed. Miscommunication and assimilationism is not the 
Segundo ela, é possível existir casos éticos e prudentes de subjetividade e comunicação não antropocêntricas em relação aos ecossistemas naturais. A tradução intercultural das representações de humanos e não humanos não deve passar por uma comunicação centrada excessivamente no homem. Ao contrário disso, sendo intercultural, liberta animais, florestas e o próprio homem de formas de opressão, ou seja, não desnaturaliza a natureza e não desumaniza o humano. Tal agência também contraria toda construção de hierarquização de espécies, valorizando a justiça ecológica. Ela trabalha pela ética, prudência e solidariedade entre os seres.

A "cross-species symbolic communication" (comunicação simbólica interespécies) admite modos de interação não verbais do homem com outros seres vivos: "O desafio da real comunicação neste nível de comunicação interespécies é para nós humanos aprender a se comunicar com outras espécies nos termos delas, em suas próprias linguagens, ou em termos comuns, se eles existem (PLUMWOOD, 2002, p. 189, tradução nossa). ${ }^{8}$ (PLUMWOOD, 2002, p. 189). Plumwood (2002) também inclui o reconhecimento da nossa animalidade decorrente da desconstrução do racionalismo, da desestabilidade da radical descontinuidade entre homem e natureza e da capacidade de intercomunicação das espécies. Ela diferencia a agência intercultural da ecologia profunda, considerando que a primeira valoriza a comunicação interespécies, enquanto a segunda se atém à postura de alguém que olha a natureza um propósito delimitado numa fenomenologia ainda centralizadora. Uma leitura agenciada de comunicação intercultural dos seres inclui a união de forças de humanos e espécies animais pela preservação da floresta e da savana, por exemplo.

Partindo desses pressupostos desenvolvidos por Val Plumwood e de comunicação co-cultural discutida por Mark Orbe, apresentaremos na próxima seção assertivas a respeito da comunicação indígena enquanto modelo de agência pós-colonial e intercultural, e suas implicações nas representações de territorialidades ambientais no jornalismo da Amazônia.

\section{Comunicação Indígena e Territorialidades na Amazônia}

Discutimos neste artigo sobre as implicações envolvidas no termo territorialidade e ausentes no conceito de território. As comunidades indígenas compreendem a legitimidade das demandas individuais e coletivas dos sujeitos presente nas lutas de demarcação de terras diante das lógicas tardomodernas e capitalistas nacionais e internacionais do

inevitable outcome, although there are as in the human case better and worse translation attempts (PLUMWOOD, 2002, p. 60).

8 "The real communication challenge at this level of interspecies communication is for we humans to learn to communicate with other species on their terms, in their own languages, or in common terms, if there are any". 
Estado e do mercado financeiro. A comunicação indígena, deste modo, não pode estar desvinculada dos valores das agências pós-coloniais etnocultural, co-cultural e intercultural, apontadas respectivamente por Spivak (1999), Orbe (1998) e Plumwood (2002). A partir de sentidos agenciados, os povos indígenas reforçam, legitimam e disseminam estereótipos de diversidade étnica, organização, resistência, manutenção das tradições mesmo em contextos urbanos, luta territorial e identitária, mobilização de forças religiosas, políticas e sociais, harmonia e comunicação com animais. Isto por meio de elaborações narrativas míticas, cantos, gestos e ritos, ideais sustentáveis e apelos preservacionistas em favor da fauna e da flora através, por exemplo, de deslocamentos de áreas agrícolas para não degradar o solo e reduzir as fontes alimentícias de espécies endêmicas.

Iremos debater as particularidades da comunicação nativa dos grupos indígenas e sua importância aos seres humanos, não humanos e a natureza. Seus sentidos etnoculturais, co-culturais e interculturais servirão de ilustração de modo que compreendamos os apelos pós-coloniais das territorialidades na região amazônica do Brasil.

Di Felice e Pereira (2017, p. 24) sinaliza para a compreensão do conceito discutido neste artigo ao tratar da interação entre território e natureza. Se eles "devem ser considerados como elementos que nos constituem como informações, substâncias e realidades materiais", dentro e fora de nós, a territorialidade condiz à construção dos sujeitos. Sua interação ecológica perpassa por uma prática comunicativa complexa e interativa do "sujeito-media-circuitos informativos-territorialidades" (DI FELICE, PEREIRA, 2017, p. 27). Ele, portanto, comunica demandas territoriais ao interagir com os ecossistemas naturais. Segundo Di Felice e Pereira (2017), os povos indígenas expandem suas territorialidades ao se apropriarem das tecnologias digitais, ultrapassando suas fronteiras geográficas. Fazem uso de um net-ativismo aliado do monitoramento das suas terras, do protagonismo e da diplomacia. As tecnologias comunicativas 
contribuem para o processo de "construção informativa do habitar", tornando as territorialidades plurais e dinâmicas (DI FELICE; PEREIRA, 2017 , p. 48). Sem prejuízo da ocupação de seus territórios, esses povos informam nas redes digitais suas demandas às suas regiões e ao mundo sem abandonar seus lugares de origem.

A territorialidade ambiental se consagra no fato de a própria floresta amazônica ser constituída "por uma variedade de ecossistemas modulados por inúmeras diversidades biológicas, culturais e sociais" (DI FELICE; PEREIRA, 2017, p. 47). A comunicação indígena, segundo o mesmo autor, faz uso da produção audiovisual. Assim, passando diretamente da linguagem oral para a midiática, legitimando a posição de produtora de conteúdos por parte de sujeitos engajados com sua cultura, produzindo um outro sentido de territorialidade conectiva, deslocada e ampliada dos espaços geográficos aos mecanismos tecnológicos, ecologicamente interativa com a fauna e a flora.

Partindo de nossas discussões teóricas e críticas aqui desenvolvidas, podemos dizer que a comunicação ambiental pós-colonial indígena legitima territorialidades humanas e não humanas integradas. O jornalismo dentro desta visão comunicacional, precisa reconhecer as limitações das rotinas da cobertura periódica e ousar através de uma perspectiva de cobertura in loco.

Victoria Lapoe e Benjamin LaPoe II (2017) defendem uma cobertura jornalística interpretativa, contextual e de imersão sobre as questões indígenas. Contextual porque o desconhecimento dos territórios pode produzir estereótipos negativos acerca dos povos e interpretativa ao focar mais nas soluções do que nas consequências, além das "native news" [notícias dos nativos] serem mais temáticas do que episódicas e imersiva, histórico e contextualmente, devido a cobrir os fatos na contramão do trabalho da grande mídia desinformada da realidade in loco das reservas indígenas. Deste modo, valendo-se apenas do jornalismo informativo, 
factual e declaratório, o profissional de mídia não pode compreender as lógicas políticas e econômicas dominantes e as demandas co-culturais engendradas pelas territorialidades complexas e problemáticas dos povos indígenas e tradicionais.

O jornalismo na Amazônia precisa considerar a sobreposição não homogênea de territórios, de acordo com Becker, e as territorialidades humanas e ambientais das diversas comunidades, de seres não humanos e da floresta. A pesquisa na área deve reconhecer os apelos políticos, econômicos, sociais, culturais e ecológicos de diferentes sujeitos e grupos minoritários em contextos sinérgicos complexos, suas estratégias não assertivas, assertivas e agressivas de comunicação interna e relacionada aos grupos majoritários expressas em discursos reproduzidos em jornais periódicos, sites noticiosos e nas produções alternativas, caso dos jornais comunitários e documentários. Também legitimar a agência etnocultural, co-cultural e intercultural de integração e harmonia das minorias entre si, nos espaços públicos de voz, com a natureza, os animais, as florestas e savanas. Os povos indígenas demonstram que as demandas por territorialidades não implicam, em geral, na degradação ambiental. O jornalismo e a pesquisa na área devem sinalizar isso como valor comum às comunidades tradicionais e às minorias na Amazônia.

O Programa de Pós-graduação em Comunicação da Universidade Federal de Roraima (UFRR), aprovado pela CAPES, no final de 2018, está num contexto de diversidade humana, étnica, animal, de planalto de baixa densidade florestal situado na região das Savanas das Guianas, de rios e igarapés, de demarcação de terras indígenas e de tentativas de avanço do agronegócio. Ele contempla disciplinas e orienta projetos de pesquisa a respeito das territorialidades amazônicas e os processos comunicacionais envolvidos nas suas representações e na sua disseminação jornalística. A proposta do programa

[...] pressupõe pensar formas de pesquisar (e intervir) que respeitem o complexo e delicado equilíbrio amazônico. Sem deixar 
de explorar, no entanto, suas múltiplas possibilidades e seus recursos simbólicos, estéticos, filosóficos etc., via problematização da identidade e da memória regional, em consonância com os processos comunicacionais aí configurados e/ou daí derivados (PROGRAMA DE PÓS-GRADUAÇÃO EM COMUNICAÇÃO DA UNIVERSIDADE FEDERAL DE RORAIMA, 2018, p. 15).

A proposta aprovada também reconhece as complexas lógicas territoriais e as territorialidades de confronto no espaço geográfico do estado mais setentrional do país.

Boa parte da área espacial de Roraima $(46,35 \%)$ é ocupada pelos 23 territórios indígenas do Estado $(104.018,00$ km²) - Raposa Serra do Sol é o maior deles. As áreas sob jurisdição da União somam $76.242,18 \mathrm{Km}^{2}(34,00 \%)$ e sob controle estadual $22.411,80 \mathrm{Km}^{2}$ $(10,00 \%)$. Os sítios de preservação ambiental ocupam mais $8,40 \%$ do território $\left(18.879,99 \mathrm{Km}^{2}\right)$ e as áreas sob controle das Forças Armadas $2.747,00 \mathrm{Km}^{2}(1,25 \%$ do total) (PROGRAMA DE PÓSGRADUAÇÃ̃O EM COMUNICAÇÃO DA UNIVERSIDADE FEDERAL DE RORAIMA, 2018, p. 17).

Essa descrição insinua a preocupação de pesquisadores em relação às sinergias urbanas, rurais e ecossistêmicas naturais do estado. A estrutura midiática local também deve ser levada em consideração.

Ela conta com "14 emissoras de rádio (02 estatais, 09 privadas e 03 comunitárias), 07 emissoras de televisão (06 privadas e 01 pública), 03 jornais e 02 revistas privadas" (PROGRAMA DE PÓS-GRADUAÇÃO EM COMUNICAÇÃO DA UNIVERSIDADE FEDERAL DE RORAIMA, 2018, p. 19), além de cinco sites de notícias mais consultados pelos roraimenses. Sua produção jornalística constitui expressiva fonte de informação sobre a realidade humana e as demandas ambientais da região.

As linhas de pesquisa do programa de pós-graduação valorizam o trabalho e o papel dos meios e das redes comunicacionais da Amazônia. A primeira Comunicação, Memória e Identidades tem interesse nas "relações entre a comunicação e as memórias sociais, políticas e culturais atuantes na constituição das múltiplas identidades amazônicas" (PROGRAMA DE PÓS-GRADUAÇÃO EM COMUNICAÇÃO DA UNIVERSIDADE FEDERAL DE RORAIMA, 2018, p. 59). A segunda linha Estudos de Mídia, Território e Processos Comunicacionais aborda "processos de comunicação 
midiatizados, atores, rotinas, ritualidades, dispositivos, digitalização, convergências, materialidades, linguagens, produtos, circulação e estratégias de interação" da reconstrução da cultura local, regional, nacional e global (PROGRAMA DE PÓS-GRADUAÇÃO EM COMUNICAÇÃO DA UNIVERSIDADE FEDERAL DE RORAIMA, 2018, p. 60).

Considerando seus objetivos e suas linhas de pesquisa, a criação do programa de pós-graduação possibilita o ensino e a pesquisa a respeito das complexas territorialidades humanas e ambientais envolvendo a população urbana e rural, as comunidades indígenas e ribeirinhas, os poderes públicos, militares, cientistas e ambientalistas, ONGs nacionais e internacionais. A percepção das lógicas territoriais oficiais e das territorialidades alternativas instiga a preocupação com problemáticas ecológicas como queimadas e desmatamentos para ocupação humana e de gado, uso de agricultura e pecuária de exploração permanente do solo inclusive por parte de indígenas, tentativas de construção de hidrelétricas e previsões de seus impactos nas comunidades tradicionais dependentes da economia pesqueira, conflito entre apelos ecológicos de comunidades indígenas e tentativas de expansão do agronegócio, perda e reserva de carbono sob atuação e influência de diversos atores e distintas etnias, violência e tráfico contra animais ameaçados ou não de extinção, (des)equilíbrios entre seres humanos e não humanos nos contextos da savanização, poluição de igarapés nos bairros da capital Boa Vista, focos de garimpagem e degradação das águas em terras demarcadas ou não, impactos do El niño na fauna e na flora precarizados pelas interferências humanas, modelos de economias tradicionais e urbanas sustentáveis entre outras.

Os pesquisadores ligados ao programa têm a possibilidade de discutir, avaliar e denunciar as representações dos diferentes sujeitos nos diversos formatos, gêneros e nas produções jornalísticas dos meios e dos profissionais do estado. O propósito deste artigo científico é sugerir fontes bibliográficas, pressupostos teóricos e críticos àqueles interessados em apontar direcionamentos a um jornalismo não meramente factual. A 
perspectiva dos estudos pós-coloniais oferece paradigmas capazes de garantir subsídios críticos acerca das complexas e crônicas territorialidades ambientais na Amazônia. Outras perspectivas teóricas podem ajudar os pesquisadores a analisar o papel de fontes oficiais e não oficiais ao referenciar as lógicas e as lutas territoriais contra ou a favor de ecossistemas naturais preservados.

\section{Considerações Finais}

Nossa proposta de discussão teórica e crítica sobre a pesquisa de territorialidades ambientais na região Norte e, mais especificamente, em Roraima contou com a apresentação de paradigmas a respeito do conceito, da comunicação das minorias e da comunicação indígena expressiva para reconhecer as políticas culturais e ecológicas de sujeitos e identidades na região. Distinguimos as perspectivas conceituais de territorialidade e território, reconhecemos o papel das agências pós-coloniais em seus aspectos etnoculturais, co-culturais e interculturais, e seus direcionamentos ambientais, além de sugerir objetos de estudo a pesquisadores interessados em avaliar as produções jornalísticas em torno das complexas, crônicas e indefinidas territorialidades amazônicas.

Esperamos que o Programa de Pós-graduação em Comunicação da Universidade Federal de Roraima possa instigar seus docentes, discentes e pesquisadores a sugerir soluções de cobertura jornalística no estado e na região. De nossa parte, defenderemos produções contextuais, interpretativas e imersivas nas realidades humanas e nas relações ecossistêmicas na natureza, de modo que as territorialidades amazônicas possam ser identificadas, analisadas profundamente e até redirecionadas devido às demandas de qualidade de vida, de democratização social, cultural e ambiental, de harmonia dos seres humanos e não humanos em favor da preservação. 


\section{Referências}

BECKER, Bertha K. Amazônia. São Paulo: Ática, 1991.

COSTA, Rogério Haesbaert da. 0 mito da desterritorialização: do "fim dos territórios" à multiterritorialidade. Rio de Janeiro: Bertrand Brasil, 2012.

DI FELICE, Massimo; PEREIRA, Eliete S. Redes e ecologias comunicativas indígenas: as contribuições dos povos originários à Teoria da Comunicação. São Paulo: Paulus, 2017.

FREITAS, Marcílio de. Nuanças da sustentabilidade: visões fantásticas da Amazônia. In: FREITAS, Marcílio de [org.]. A ilusão da sustentabilidade. Manaus: Governo do Estado do Amazonas, 2003.

LAPOE, Victoria L.; LAPOE II, Benjamin Rex. Indian country: telling a story in a digital age. East Lansing: Michigan State University Press, 2017. E-book.

MARTIN-BARBERO, Jesús. Ofício de cartógrafo: travessias latino-americanas da comunicação na cultura. São Paulo: Edições Loyola, 2004.

MORIN, Edgar. Terra-pátria. Porto Alegre: Sulina, 2003.

ORBE, Mark P. Constructing co-cultural theory: an explication of Culture, Power, and Communication. Thousand Oaks; London; New Delhi: Sage Publications, 1998.

PLUMWOOD, Val. Environmental culture: the ecological crisis of reason. New York: Routledge, 2002.

PROGRAMA DE PÓS-GRADUAÇÃO EM COMUNICAÇÃO DA UNIVERSIDADE FEDERAL DE RORAIMA. Projeto de criação do Programa de Pós-graduação em Comunicação. Boa Vista/RR, 2018.

SAQUET, Marcos Aurélio. Abordagens e concepções de território. 2 ed. São Paulo: Expressão Popular, 2010.

SOUSA, Cássio Noronha Inglez de; ALMEIDA, Fábio Vaz Ribeiro de [orgs.]. Gestão territorial em terras indígenas no Brasil. Brasília: Ministério da Educação, Secretaria de Educação Continuada, Alfabetização, Diversidade e Inclusão; Unesco, 2015.

SPIVAK, Gayatri C. A critique of postcolonial reason: toward a history of the vanishing present. Cambridge: Harvard College, 1999. 